\title{
Enhancing Student Cognition and Affect through the Creative Art of Struc- tural and Civil Engineering
}

\section{Dr. Evelyn Hanna Laffey, Princeton University}

Dr. Evelyn Hanna Laffey is the Associate Director of the Princeton University Council on Science and Technology. Previously, she served as the Assistant Dean for Engineering Education at the Rutgers University School of Engineering. She has a bachelors degree in mathematics and doctorate in mathematics education from Rutgers University. She has over fifteen years of experience working with K-16 students and educators. She is interested in exploring the intersection of cognition, affect, and identity within STEM education and operationalizing research findings to provide an excellent and equitable education to all students.

\section{Dr. Maria E. Garlock, Princeton University}

Maria Garlock is an Associate Professor at Princeton University in the Department of Civil and Environmental Engineering where she is the Director of the Architecture and Engineering Program. Her scholarship is in resilient building design and in studies of the best examples of structural designs of the present and past. She has co-authored the book Felix Candela: Engineer, Builder, Structural Artist and has recently launched a MOOC titled "The Art of Structural Engineering: Bridges."

\section{Dr. Aatish Bhatia, Princeton University}

Aatish Bhatia is an Associate Director (Engineering Education) in Princeton University's Council on Science and Technology. He works with faculty in engineering and related disciplines on incorporating active learning in the classroom and bringing science and engineering to a wider audience. 


\section{Enhancing Student Cognition and Affect through the Creative Art of Structural and Civil Engineering}

\section{Introduction}

National discourse on STEM education urges educators to attend to the growing demand for a STEM-literate populace. At Princeton University, we aim to advance STEM-literacy of all undergraduates, regardless of major, by offering a rich variety of courses that enhance content knowledge, attend to student affect, and explore the societal impact of STEM. The purpose of this evidenced-based practice paper is to report on the impact of the Princeton University's Structures and the Urban Environment (heretofore Structures) course on students' cognition and affect. The Structures course is one component of a multi-institutional, NSF-funded educational project, the Creative Art of Structural and Civil Engineering (CASCE).

With an enrollment of approximately 150 students, the Structures course aims to enhance cognition within the domain of STEM-literacy for students majoring in engineering, the humanities, or social sciences. Additionally, the course aims to positively impact students' affect by attending to their motivation, attitudes, beliefs and self-efficacy towards STEM content and engineering as a creative profession. With fewer than $40 \%$ of college students intending on majoring in STEM graduating, there is a need to address retention and graduation in higher education ${ }^{1}$. Furthermore, as noted by the $\mathrm{NAE}^{2}$ and the $\mathrm{ASEE}^{3}$ it is important for all students to appreciate the central role of engineering in all facets of modern life. The civil engineering ideas disseminated by the Structures course are vital to STEM majors and students majoring in the humanities and social sciences alike, because civil engineers design and build the systems that give us shelter (buildings), enable transportation (roads, bridges, ports), and bring us water and power (dams, reservoirs). In addition to ensuring the content was accessible to all students, the faculty utilized evidenced-based teaching practices with the aim of enhancing students' cognition and affect, as well as addressing retention and overall student satisfaction ${ }^{4}$.

Three research questions guided the evaluation: (1) As reported by the students, to what extent did the course enhance students' STEM-literacy? (2) How did the course impact students' affect with regards to their motivation, attitudes, beliefs, and engineering self-efficacy? (3) To what extent did the use of evidence-based teaching practices impact the student experience in the Structures course? To answer the guiding research questions, we utilized a mixed-method approach to collecting and analyzing quantitative and qualitative data. The following sections describe the theoretical framework guiding the evaluation, the analytical methodology, preliminary findings, and future work.

\section{Theoretical Framework}

A two-pronged theoretical framework guided the study. First, we explored the notion of STEMliteracy for the $21^{\text {st }}$ Century. Second, we aimed to define and use constructs of affect to

\footnotetext{
i This material is based upon work supported by the National Science Foundation under Grant No. NSF 14-32426, 14-31717, and 14-31609. Any opinions, findings, conclusions or recommendations expressed in the materials provided are those of the author(s) and do not necessarily reflect the views of the National Science Foundation.
} 
understand and assess the students' STEM affect. Each component of the theoretical framework is described in the following paragraphs.

STEM-literacy for the $21^{\text {st }}$ Century is multifaceted and includes content knowledge and habits of mind $^{5}$. For the purpose of this study, we refer to STEM-literacy as the union of students' understanding of STEM content and their ability to reason critically about structures using civil engineering principles. The STEM content relevant to the Structures course was communicated with three perspectives essential to understanding structural engineering: the scientific, the social, and the symbolic. Any introductory course needs to recognize that engineers are disciplined by nature and by society. At the same time, the most creative engineers are free to explore designs that represent a freedom of expression. The course also characterizes the social conditions in which engineers operate, by contrasting designs in different nations and illustrating how social and cultural contexts influence the design of structures.

Extensive research indicates that utilizing student-active pedagogy and improving facultystudent interaction contribute to an increase in cognitive gains, student satisfaction and persistence ${ }^{6}$. Borrego, Froyd and Hall provide a concise summary of student-active pedagogy in stating "At its core, an instructor using a student-active pedagogy designs the class meeting so that students are routinely involved in tasks other than taking notes from a lecture." "To enhance student learning and affect in the Structures course, the faculty utilized student-active pedagogy to engage students during class time, which reduces the amount of time the professor lectures. The faculty aimed to more actively engage students in various components of the class and provide frequent feedback to the students.

We reviewed literature from philosophy, cognitive psychology, and behavioral psychology to explore affect as a possible heuristic. Affect can be described as tags in people's mind that correspond to a positive or negative event or object. We "consult or refer to an 'affect pool' containing all the positive and negative tags consciously or unconsciously associated with the representations..." ${ }^{8}$ These positive or negative tags may influence an individual's judgment and decision-making ${ }^{9,10}$. For example, students may decide to continue pursuing STEM studies if they had prior positive experiences in or successes with a STEM course. In conceptualizing affect as a heuristic, we aimed to identify measurable constructs of affect.

Exploring affect in the STEM education literature ${ }^{11}$, we identified possible constructs. For the purpose of this study, the constructs of affect are: interest, motivation, attitude, and self-efficacy. Interest reflects the level of student engagement or reengagement with the STEM content presented in the Structures course. Motivation triggers or maintains a students' goal-orientated behavior to further engage with STEM content. Students' attitude, positive or negative, provides an evaluation about the content presented in Structures. Students' self-efficacy for STEM content reflects their expectancy about his or her ability to do well on a specific STEM-related task.

Utilizing the framework defining STEM-literacy and student affect, we adapted existing survey and interview protocols ${ }^{12,13}$ to evaluate the impact of the Structures course. These instruments were designed to garner students' perspective on their STEM content learning gains, as well as the extent to which the course impacted student affect. We were also interested in understanding the student perspective on the use of evidenced-based teaching practices. The following section describes the analytical methodology, which is followed by a discussion of the preliminary 
findings.

\section{Analytical Methodology}

To understand the impact of the Structures course, three research questions guided the analytical framework: (1) As reported by the students, to what extent did the course enhance students' STEM-literacy? (2) How did the course impact students' affect with regards to their motivation, attitudes, beliefs, and engineering self-efficacy? (3) To what extent did the use of evidence-based teaching practices impact the student experience in the Structures course? We designed and implemented a mixed-methods study to evaluate the impact of the Structures course. Quantitative data was collected in the form of course grades and surveys to measure impact on cognition and affect. Focus groups and open-ended questions on surveys garnered qualitative data. To ensure limited bias, the first author, who is not affiliated with the teaching team administered the survey and conducted the focus groups.

The Student Assessment of Learning Gains (SALG) ${ }^{14}$ survey was adapted and administered to the Structures course. The Structures course is open to students of all majors. In the spring 2015 semester, 149 students enrolled in the course. Approximately $60 \%$ of the students were majoring in the humanities or social sciences and $40 \%$ were natural science or engineering majors. The survey was administered during the last two weeks of classes and 65 students completed the survey, which equates to a response rate of $44 \%$.

The survey contained four open-ended questions. We received 260 responses to the 4 questions (116 open-ended questions were left unanswered). In the last third of the semester, the first author on this paper, recruited and conducted focus groups. Two students engaged in individual interviews and three additional students volunteered to participate in a focus group. The responses from the open-ended questions on the survey, as well as data from the interviews and focus group were analyzed using principles of Grounded Theory ${ }^{15}$ and an Analytical Framework for Video Data ${ }^{16}$.

The preliminary analysis of the quantitative data resulted descriptive statistics that evidence the impact of the Structures course on STEM content knowledge and affect. Identifying emerging themes when coding the qualitative data provide a narrative describing the students' experience with the Structures course. The following section presents the preliminary findings from the analysis of the quantitative and qualitative data.

\section{Preliminary Findings}

Each section of the survey attended to one or more of our guiding research questions. First, we were interested in the extent to which the course enhanced students' STEM-literacy. Second, we wanted to understand the impact of the course on students' affect. Lastly, because the teaching team employed evidenced-based teaching practices, we offered survey questions to assess the impact of pedagogy on students' overall experiences with the Structures course.

One set of questions provided students with an opportunity to self-report learning gains on course content topics. Table 1 lists the questions in the aforementioned survey sections and 
Figure 1 summarizes student responses. The analysis of the quantitative data revealed that $97 \%$ of students reported a moderate to great gain in their ability to relate the form of a structure that they encounter in everyday life to the its function and to the forces in the structure; and $78 \%$ of students reported a moderate to great gain in their STEM abilities (understanding of STEM content and increase in STEM-related skills).

Your understanding of class content

1. As a result of your work in this class, what GAINS DID no gains a little gain moderate gain good gain great gain not applicable
YOU MAKE in your UNDERSTANDING of each of the
following?
1.1 Evaluate and contextualize significant works of civil
engineering based on their social, scientific and
symbolic importance
1.2 Trace the development and innovation of new
materials, and describe how these materials gave rise to
new forms
1.3 Compare, contrast, and critique structures as works
of structural art
1.4 Relate the forms of bridges, skyscrapers and other
structures that you encounter in daily life to their function
and to the forces in the structure
1.5 How ideas from this class relate to ideas
encountered in non-civil engineering classes
1.6 How studying this subject area helps people address
real world issues
1.7 Please comment on HOW YOUR
UNDERSTANDING OF THE SUBJECT HAS CHANGED
as a result of this class.

Increases in your skills

2. As a result of your work in this class, what GAINS DID no gains a little gain moderate gain good gain great gain not applicable YOU MAKE in the following SKILLS?

\begin{tabular}{|c|c|c|c|c|c|c|}
\hline $\begin{array}{l}2.1 \text { Develop a solution to an engineering design problem } \\
\text { by exploring different alternatives within a set of } \\
\text { constraints }\end{array}$ & 0 & 0 & 0 & 0 & 0 & 0 \\
\hline $\begin{array}{l}2.2 \text { Synthesize and apply the lessons gained from } \\
\text { engineering failures }\end{array}$ & 0 & 0 & 0 & 0 & 0 & 0 \\
\hline $\begin{array}{l}\text { 2.3 Rank design alternatives based on sustainability and } \\
\text { environmental impact }\end{array}$ & $\bigcirc$ & 0 & $\bigcirc$ & 0 & 0 & 0 \\
\hline $\begin{array}{l}2.4 \text { Evaluate case studies in engineering based on } \\
\text { social, scientific and symbolic criteria }\end{array}$ & 0 & $\bigcirc$ & 0 & 0 & 0 & 0 \\
\hline $\begin{array}{l}2.5 \text { Please comment on what SKILLS you have gained } \\
\text { as a result of this class. }\end{array}$ & & & & & & \\
\hline
\end{tabular}

Table 1: Survey Questions Related to STEM Content and Skills 

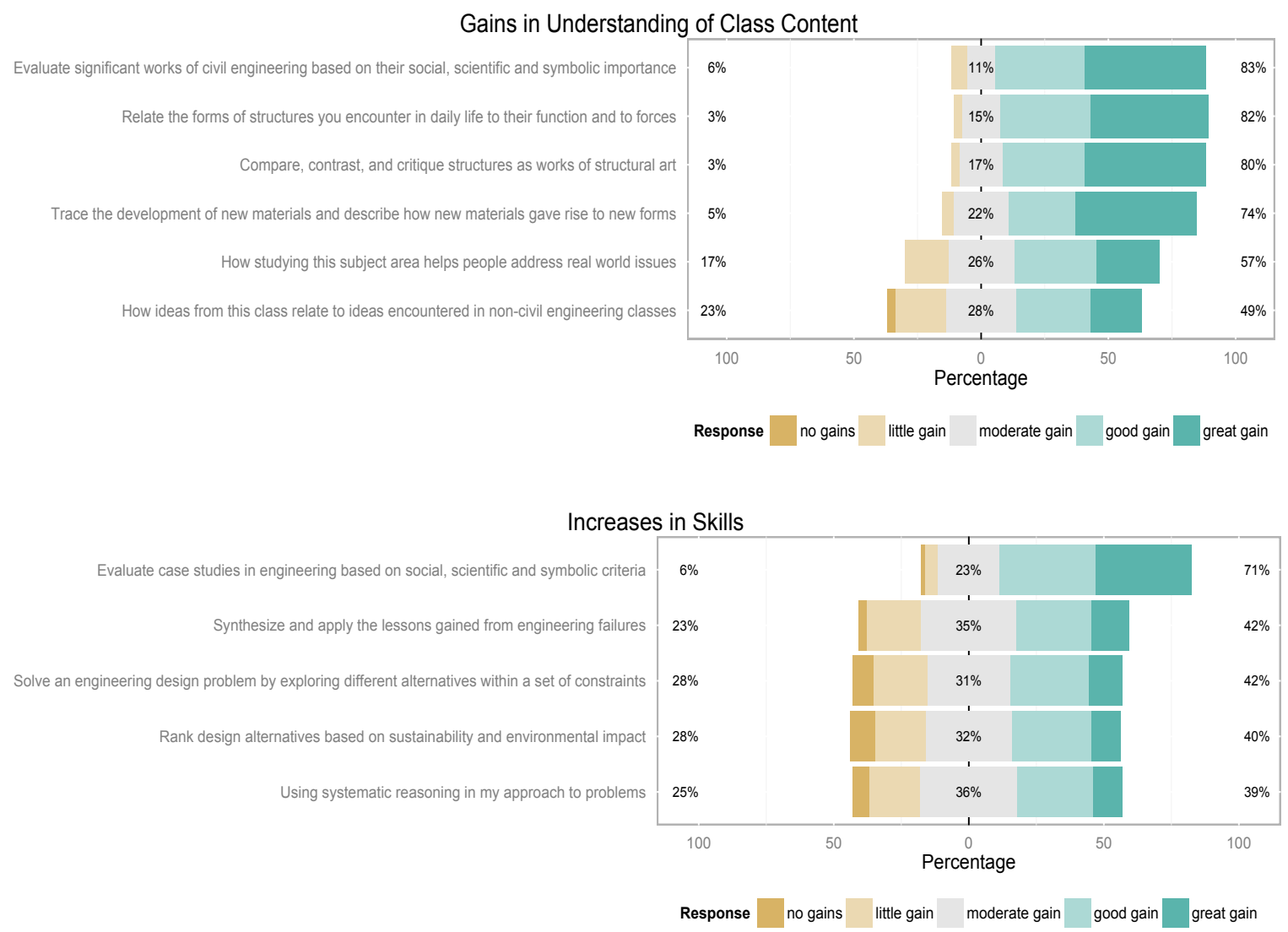

Figure 1: Summary of Responses Related to STEM Content Knowledge and Skills

The section of questions on the survey that related to student affect was labeled "Impact on Attitudes." The specific questions posed on the survey are presented in Table 2. Overall, 95\% of students reported a technical and aesthetic appreciation for structures; $89 \%$ of students experienced moderate to great gain in interest in engineering; $86 \%$ reported moderate to great gain in confidence that they understand the material; and $83 \%$ indicated moderate to great gain in understanding how engineering helps people address real world issues. Figure 2 provides a summary of responses to the questions related to student affect. 
Class impact on your attitudes

3. As a result of your work in this class, what GAINS DID no gains a little gain moderate gain good gain great gain not applicable YOU MAKE in the following?

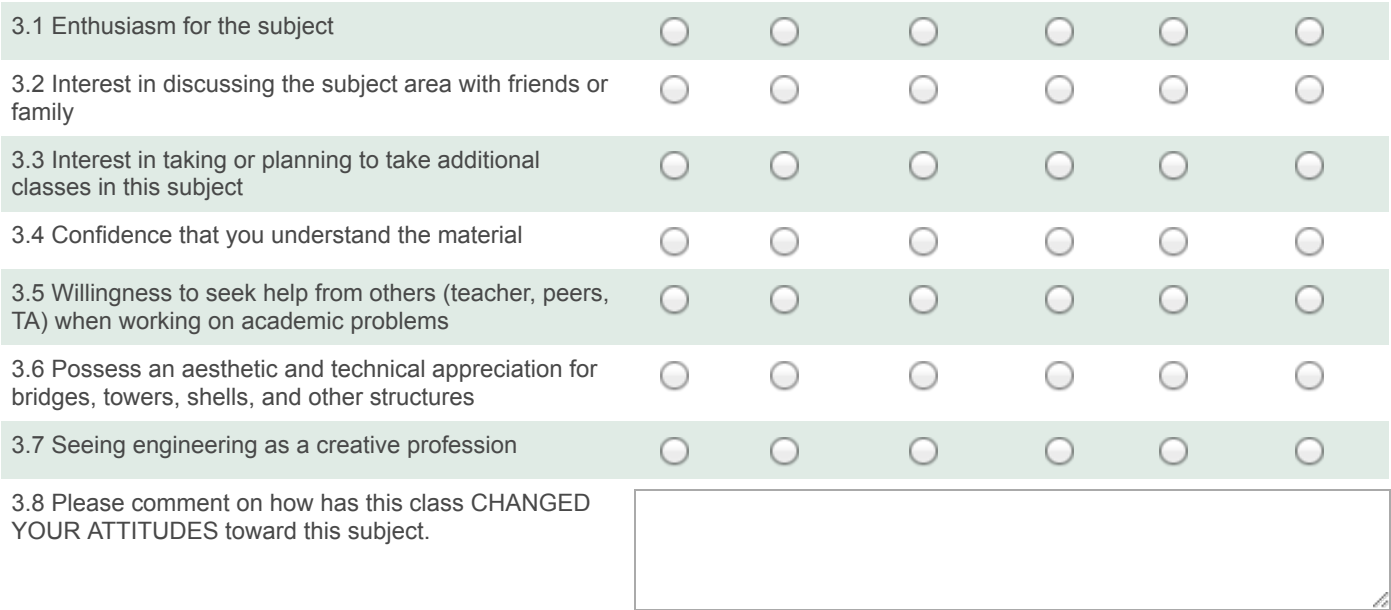

Table 1: Survey Questions Related to STEM Content and Skills

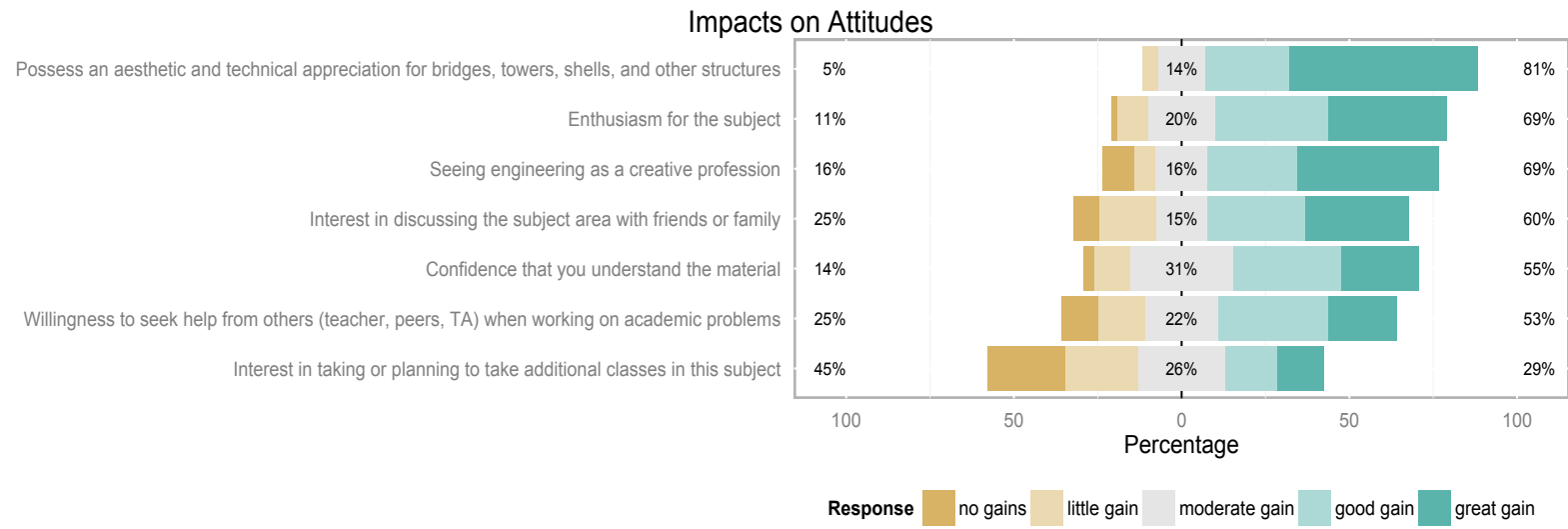

Figure 2: Summary of Responses Related to Student Affect

The section of questions on the survey that related to evidenced-based teaching practices was labeled "Use of Pedagogy." The specific questions posed on the survey are presented in Table 3. Overall, 95\% of students reported a technical and aesthetic appreciation for structures; $90 \%$ of students experienced moderate to great gain in learning because of the teaching practices; $83 \%$ reported moderate to great gain in learning because of the hands-on activities; and $87 \%$ indicated moderate to great gain in learning because of their participation in class discussions during lecture, precept, or labs. Figure 3 provides a summary of responses to the use of various pedagogical techniques and course components. 


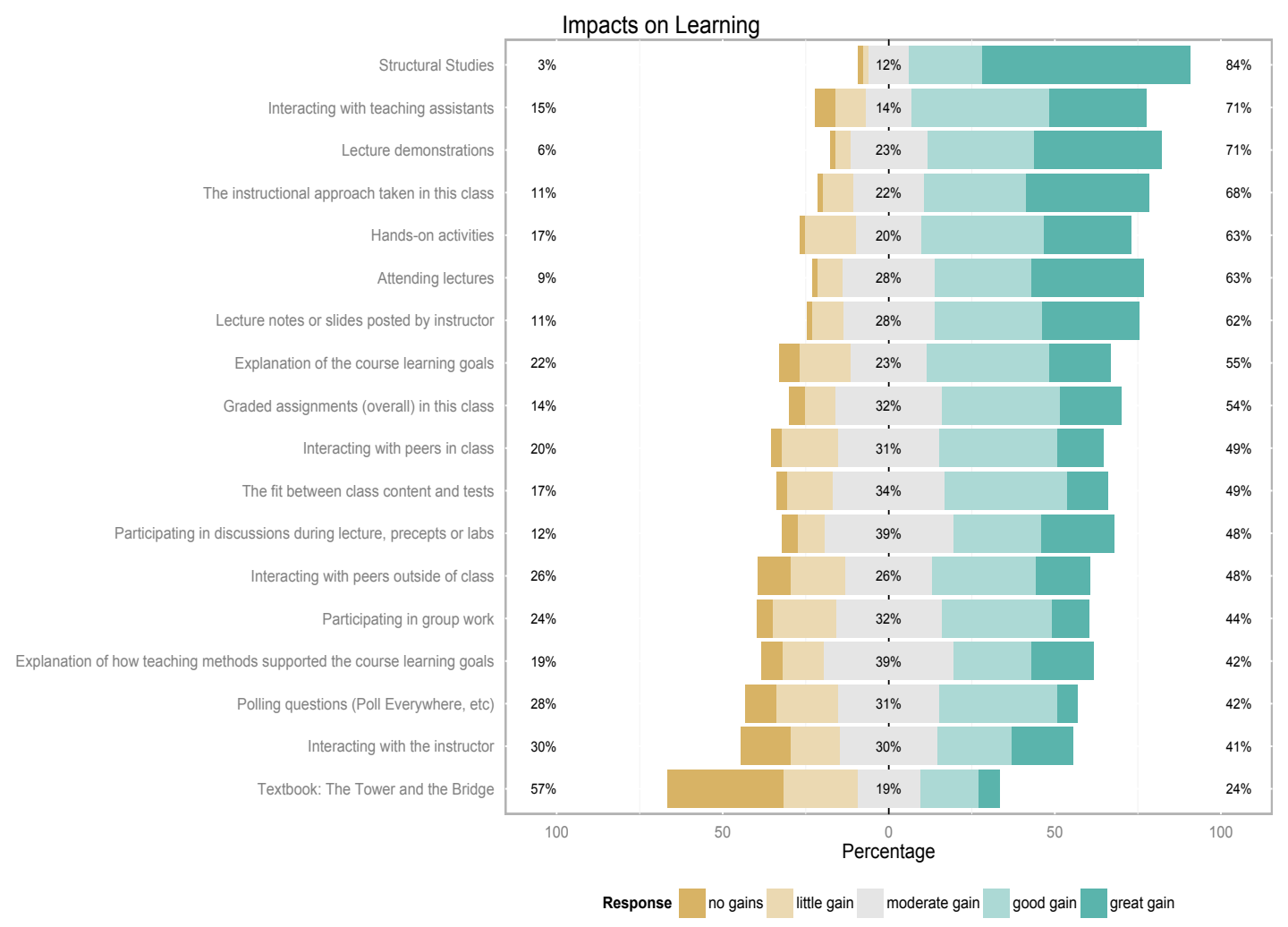

Figure 3: Summary of Responses Related to Use of Various Pedagogical Techniques

To further probe the student experience, we invited students to participate in one-on-one interviews or focus groups. Three overarching themes emerged from inductively coding the qualitative data: (1) relating course content to everyday life, (2) evolving perception of engineering, and (3) enhancing STEM abilities. We describe each of the themes in the following paragraphs and provide examples from the data.

The Structures course aims to enhance students' appreciation and understanding of the built world around them. During the interviews/focus groups and on the open-ended survey questions, we asked students to reflect on how their understanding of the built world changed, if at all, because of the Structures course. As illustrated by these two responses to an open-ended survey question, students spoke about their heightened awareness of a structure being more than the built object itself: Seeing structures in everyday life, I now understand the context behind them and how they work; and I now appreciate the economy of structures and the engineering and aesthetics that go into the structures I see in my daily life.

We were interested in understanding the impact of the course on students' attitudes towards and beliefs about engineering. We found an increase in motivation to pursue engineering as a result of the course. For example, one engineering students stated:

In a lot of other civil engineering class, it's like, ok, here's this and here are the forces on it and now, here's a truss and find all the normal forces on the truss. Verses like, this is kind of like, more overview of all the different types of buildings and bridges. It's really nice. After taking some of the more technical courses, it's nice to have the counterpart of 
like why we're doing all this, is really nice [interview; Raven; 4/23/2015; 1:34 - 2:02]. From engineering and non-engineering students alike, we found an increased interest in engineering, as illustrated by this response to one of the open-ended survey questions: I have $a$ much greater appreciation for structural art and feel more interested in it [survey response]. On the survey and during the interviews/focus groups, students described engineering as a creative profession. A student explained:

I didn't have an opinion on engineers before, not having any in my family, except for electrical engineering. I thought that they mainly had to do with technology and that is what they did. So, I guess, it definitely changed my opinion on engineers. I know that one of the objectives of the course was to prove that engineering is also very creative field and I definitely agree with that now [focus Group; Jess; 5/11/2015; 18:03-18:30]. We found that the students' reflections on engineering were well aligned with a course goal to change students' attitudes towards and understanding of the engineering profession, as evidenced by this statement: This course definitely made me respect the work of structural engineers as more than just a 'plug-and-chug' profession. There's a lot more creativity and factors they consider that I hadn't realized [survey response].

Within the domains of cognition and affect, the course seemed to decrease anxiety towards science. A self-identified English major stated: I thought that the science of structures would be really hard to understand for someone with an english[sic]/history mind like me but it turns out that civil engineering is not too intimidating [survey response]. Furthermore, when responding to questions specifically about STEM abilities (content knowledge, skills, and habits of mind), students acknowledged an increase in content knowledge. For example, a student stated: $M y$ understanding of the subject has increased especially in terms of evaluated civil engineering structures and understanding the basic science behind how they work [survey; 4/29/2015]. Another student noted: I definitely now understand how engineering is really a way of problemsolving in interesting, creative ways [survey response]. One goal of the course was to introduce "aesthetics" as a design constraint. Anecdotally, in the past, we heard from engineering students that they had not previously been cognizant of aesthetics as a design constraint. When asked to reflect on this specific constraint, one student stated: I have definitely become more aware of structural art around me and their function, specifically the flow of forces and how they carry loads [survey response]. Overall, we found that students were more confident in their ability to evaluate a structure on its aesthetics and calculate the relevant forces.

\section{Discussion}

To evaluate the impact of the Structures course, we sought to answer three research questions guided: (1) As reported by the students, to what extent did the course enhance students' STEMliteracy? (2) How did the course impact students' affect with regards to their motivation, attitudes, beliefs, and engineering self-efficacy? (3) To what extent did the use of evidence-based teaching practices impact the student experience in the Structures course? Based on the data presented in the section above, we now turn to answering the three research questions.

Our first guiding research question aimed to understand the impact of the course on students' STEM-literacy. Specifically, we were interested in their self-reported learning gains and narrative describing the course. A majority of the students reported moderate to great gain when 
responding to survey questions assessing learning gains in STEM content knowledge and related skills. The students majoring in the humanities and social sciences indicated, "civil engineering is not too intimidating" [survey response]. In other words, the STEM content was accessible to students majoring in the humanities and social sciences. Furthermore, as described the civil engineering undergraduate students, the content added value to the traditional components of the undergraduate civil engineering program.

The second guiding research question focused on student affect towards STEM. Specifically, we interested in understanding how the course impacted students' interest in, attitudes towards, and confidence with principles of structural engineering. Furthermore, we were interested in assessing the extent to which students viewed engineering as a creative profession, as that is one of the goals of the course. Overall, students reported increased gains in their interest in and attitudes towards engineering, in general, and engineering as a creative profession. Students reported gains in their confidence in related STEM abilities and recognized a connection between engineering and their everyday lives.

Lastly, we explored the relation between teaching pedagogy and students' self-reported learning gains. We found that the use of diverse teaching pedagogies may have lead to students' reporting greater learning gains. This finding aligns with existing literature that evidences learning gains linked to the use of student-active pedagogy ${ }^{4,5}$. Most notably, we found that students reported moderate to great learning gains because of their interaction with the faculty, engagement in group work and hands-on activities during class, and discussion of course learning goals.

In the current paper, we discussed our theoretical framework, analytical methodology, and preliminary findings. Our future work includes continuing to analyze data from the first year of the project. Also, over the next three years, we will collect and analyze data from future offerings of the Structures course and from the two other courses at our partner institutions.

\section{References}

\footnotetext{
${ }^{1}$ PCAST (2012). Report To The President Engage To Excel: Producing One Million Additional College Graduates With Degrees In Science, Technology, Engineering, And Mathematics. Executive Office of the President

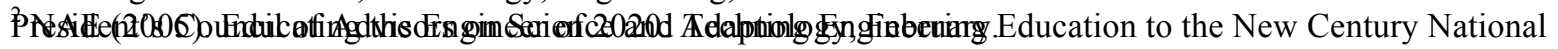
Academy of Engineering of The National Academies, The National Academies Press, Washington, DC.

${ }^{3}$ ASEE (2012). "The Green Report - Engineering Education for a Changing World", American Society for Engineering Education. https:/www.asee.org/papers-and-publications/publications/The-Green-Report.pdf.

4 Felder, R., (1995). A longitudinal study of engineering student performance and retention, IV. Instructional methods and student responses to them. Journal of Engineering Education, 84(4): p. 361-367.

${ }^{5}$ Zollman, A. (2012), Learning for STEM Literacy: STEM Literacy for Learning. School Science and Mathematics, 112: $12-19$

${ }^{6}$ Bjorklund, S. and Fortenberry, N.L. (2005). "Measuring Student and Faculty Engagement in Engineering Education" Center for the Advancement of Scholarship on Engineering Education (CASEE), National Academy of Engineering. August.

${ }^{7}$ Borrego, B., Froyd, J. E. \& Hall, T. S. (2010). Diffusion of Engineering Education Innovations: A Survey of Awareness and Adoption Rates in U.S. Engineering Departments. Journal of Engineering Education, p188
} 
${ }^{8}$ Slovic, P., Finucane, M. L., Peters, E., \& MacGregor, D. G. (2007). The affect heuristic. European Journal of Operational Research, 177, 1333-1352.

${ }^{9}$ Cohen, J. \& Fulkerson, M. (2014). Affect, Rationalization, and Motivation. Rev. Phil.Psych., 5.

${ }^{10}$ Epstein, S. (1994). Integration of the cognitive and psychodynamic unconscious. American Psychologist, 49.

${ }^{11}$ Fortus, D. (2014). Attending to Affect. Journal of Research in Science Teaching, 51, (7), 821-835.

${ }^{12}$ Purzer, S. (2011). The Relationship Between Team Discourse, Self-Efficacy, and Individual Achievement: A Sequential Mixed-Methods Study. Journal of Engineering Education, 100, (4), 655-679.

${ }^{13}$ Jones, B, D., Paretti, M. C., Hein, S. F., \& Knott, T. W. (2010). An Analysis of Motivation Constructs with FirstYear Engineering Students: Relationships Among Expectancies, Values, Achievement, and Career Plans. Journal of Engineering Education, 319-336.

${ }^{14}$ Seymour, E., Wiese, D., Hunter, A. \& Daffinrud, S.M. (Marzo del 2000). Creating a Better Mousetrap: On-line Student Assessment of their Learning Gains. Paper presentation at the National Meeting of the American Chemical Society, San Francisco, CA.

${ }^{15}$ Strauss, A. \& Corbin, J. (1998). Basics of Qualitative Research: Techniques and Procedures for Developing Grounded Theory. SAGE Publications: Thousand Oaks, CA.

${ }^{16}$ Powell, A. B., Francisco, J. M., \& Maher, C. A. (2003). Analytical model for studying the development of learners' mathematical ideas and reasoning using videotape data. Journal of Mathematical Behavior, 22(4), 405-435. 